Gilberto Bosques

\title{
La Escuela de Rabindranath Tagore: Shantiniketan
}

\author{
(De La Antorcha México)
}

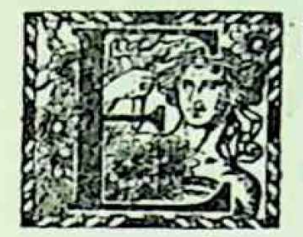

L Marharshi Devendranath Tagore, padre del poeta, viajaba por una región de campo llano en que merodeaban los bandidos más audaces de la India. Un dia reclinó sus fatigas en la sombra de tres árboles hermanos, en cuyas altas ramas culminaba la belleza incomparable del paisaje. Y sintió que aquellos árboles acendraban y elevaban su espiritu más que

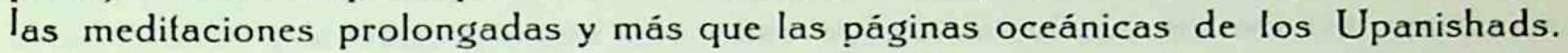
Alli plantó su tienda y se entregó a la oración. Una paz perlecta penetraba todas las cosas.

Más tarde, aquel lugar. situado a treinta y tres leguas de Calcuta. fué Shantiniketan-mansión de paz. A la sombra de los tres árboles tendidos al infinito se elevó un santuario del bosque, sashram;. donde no había imagen alguna ni se practicaban ritos, porque estaba abierto a todos los creyentes del mundo.

El poeta Rabindranath Tagore quiso aprovechar para fines educativos la poderosa influencia del paisaje en los espíritus: y fundó en Shantiniketan la actual escuela de Bolpur, donde se ensayan interesantes métodos.

En la escuela se dan las clases al aire libre, siguiendo la tradición de la India, donde los antiguos maestros de la sabiduría-que vivian en el bosquecongregaban a sus discipulos en la margen de algún río sagrado. para decirles su verdad, para unirlos a la armonia de la Creación. palpitante en torno de ellos. para moverlos a pensar en los problemas de la Vida y para fortalecerlos en el amor universal.

El pensamiento de Rabindranath Tagore, al fundar esta escuela, ha sido educar en un hogar-santuario. combinando científicamente las formas de desarrollo espiritual del viejo sistema hindú econ los más sanos principios de los métodos modernos.

Según Pearson, el reglamento diario de la escuela es el siguiente: .Se despierta a los muchachos antes de salir el sol, con una de las canciones del poeta. que canta un grupo de ellos. Al momento van a su baño matutino. para el cual utilizan los pozos que hay en los alrededores. Luego tienen quince minutos de retiro para la oración silenciosa, que hacen sentados bajo los árboles o en el campo abierto del alba; y terminada la oración se reunen y cantan los versos sánscritos que escogió el Marharshi Devendranath Tagore de los Upanishads. Toman luego un piscolabis, y a las siete comiezan las clases, las cuales, como no hay salas para ello, se dan al aire libre o en las galerias de los pabellones. cuando llueve. Se almuerza a las once y media, y en las horas de calor; los muchachos se están en sus cuarlos y estudian y discuten sus lecciones, ayudados por los maestros, que 
los acompañan por si son necesarios. Para ciento cincuenta alumnos que tiene la escuela hay veinte maestros. Las clases se reanudan a las dos de la tarde y siguen hasta las cuatro y media. Con la fresca unos juegan al futbol y otros salen de paseo con sus maestros. Al ponerse el sol, vuelven a tener un cuarto de hora de silencio y canto de los versos vespertinos; y algunos muchachos van a la escuela nocturna, fundada para los criados de Shantiniketan y para la gente del campo vecino. Antes de la cena se dedica una hora para cualquier entretenimiento. como por ejemplo, contar cuentos, que los cuentan los maestros, dar conferencias con proyecciones, o bien algo pensado por los propios muchachos. A las nueve suena la campana del retiro. y la mayoría de los muchachos está ya dormida a las nueve y media, menos en las noches de luna, en las cuales los mayores se van de paseo por los bosques vecinos, donde se sientan a cantar.

La escuela no tiene director: está bajo un comité ejecutivo elegido por los maestros, uno de los cuales se escoge cada año como presidente y lleva la parte administrativa. Para cada asignatura hay un maestro director. Los libros y métodos de enseñanza son discutidos por todos los maestros de una asignatura, pero el director de ella está en libertad de resolver por su cuenta lo que mejor le parezca.

-A los muchachos se les permite, con toda confianza. ocuparse de sus propios asuntos. Tienen su comité para cada sección, y reuniones generales cuando hay que discutir asuntos que afectan a toda la escuelas.

La educación que se imparte en esa escuela es verdaderamente integral. como no la abarca la petulante pedagogia de nuestros maestros. Alli se desarrollan cuidadosamente todas las lacultades humanas. En cultura física. los muchachos de la escuela de Bolpur han obtenido siempre los primeros premios en los juegos olímpicos interescolares de la región. Viven con el vigor de la naturaleza que los rodea a todas horas. La educación intelectual es completa y práctica: muchos exalumnos ocupan puestos prominentes en el seno de instituciones bancarias y comerciales de Europa. Este resultado echa por tierra el error de algunos críticos que creen ver en la escuela de Shantiniketan un plantel donde sólo se cultivan los sentimientos religiosos. Las canciones y los cuentos y las comedias del poeta enseñan a los niños todas las bellezas de la vida; y sus facultades estéticas se desarrollan en círculos de encanto. Viven en un hogar alegre y tranquilo. donde todos son hermanos-los maestros, hermanos mayores-: admiran y aman todas las cosas. Su moral. sin egoísmos mezquinos, es fuerte y clara. Además, se realiza la educación del subconsciente en los niños. Esto es lo más importante, a nuestro juicio. de la inteligente labor pedagógica de los maestros de Bolpur.

En próximo artículo diremos algunas palabras respecto a tan interesante cuestión educativa.

G. B. 